\title{
A comparative property investigation of lithium phosphate glass melted in microwave and conventional heating
}

\author{
AVIK HALDER, BISWAJIT MANDAL, SOURINDRA MAHANTY, RANJAN SEN and \\ ASHIS KUMAR MANDAL* \\ CSIR-Central Glass and Ceramic Research Institute, Kolkata 700032, India \\ *Author for correspondence (ashis@cgcri.res.in; ashismand@gmail.com)
}

MS received 6 September 2016; accepted 23 November 2016; published online 16 August 2017

\begin{abstract}
The present study addresses the application of microwave (MW) energy for melting lithium phosphate glass. A comparative analysis of the properties is presented with glasses melted in conventional resistance heating adopting standard methods of characterization. The density of the glass was found less in MW heating. The glass transition temperature was recorded as $3-10^{\circ} \mathrm{C}$ lower in MW prepared glass than in conventional glass. Micro-hardness is found to be improved in case of MW heating. Maximum forward power was recorded less than $2 \mathrm{~kW}$ with an average power $\sim 1 \mathrm{~kW}$ during melting of $40 \mathrm{~g}$ glass in MW furnace. MW forward and reflected power measured during melting in the MW cavity was elaborated. Total melting time was within $2 \mathrm{~h} 30 \mathrm{~min}$ in MW heating, whereas it was 6-7 h in resistive heating. Total power consumed was $\sim 5 \mathrm{kWh}$ in MW heating and $\sim 14 \mathrm{kWh}$ in resistance heating.
\end{abstract}

Keywords. Microwave heating; lithium phosphate glass; forward power; reflected power; glass transition temperature.

\section{Introduction}

Exploration of alternate material processing tools continues mainly due to the quest for improving properties, energy efficiency and to overcome challenges in practiced processes. Microwave (MW) material processing technology is a futuristic technology applicable to various types of material processing owing to its several advantages over conventional material processing techniques. Improved properties of material could be successfully processed using this route [1-5]. Many excellent reviews explore its wide applications in material processing and some of them lead to upscaling in the industrial scale [6-10]. Sintering of materials [11], preparation of lithium ion conductor [12] and ceramics [13] were achieved using heating method.

However, MW processing of bulk glass is a relatively recent development and a few selected compositions have been investigated in the laboratory scale by the authors' group [14-17]. Phosphate glass finds its attraction mainly due to its low melting point, high solubility of dopant ions and versatile applications [18]. Phosphate glasses doped with metals like Fe showed high chemical durability, which make them potential candidates for nuclear waste immobilization [19]. Low refractive index and low dispersion phosphate glasses are preferred in optical elements [20]. Alkali lithium phosphate glass is one of the basic prototype glasses in solid-state electrolyte, because of its high electronic and ionic conductivity at room temperature [21]. MW melted phosphate glass exhibits low dispersion, low density and low glass transition temperature compared to conventionally heated alumina phosphate glass [22].

In MW processing, energy is directly deposited to materials through molecular interaction with the electromagnetic field unlike in conventional heating, where energy is transferred to the material through convection, conduction and radiation of heat [23]. Volumetric heating by MW absorption contributes a rapid and uniform heating within the material. Usually main advantages of MW processing are generally energy efficiency and less processing time [24]. Glasses comprise of different ingredients depending on its properties and major components are poor MW absorbers. Thus, heating the glass or batch with MW radiation is difficult at room temperature. Moreover, a significant portion of energy will be reflected and wasted within the cavity without being absorbed by the material. However, energy loss due to reflection within the cavity is not discussed in detail for glass making.

Thus, the aim of this investigation is to prepare lithium phosphate glasses using MW heating and to discuss the comparative analysis of properties with conventional glasses. The study also presents a detailed analysis of forward power and reflected power during glass melting in MW heating and compares the power requirement with resistive heating.

\section{Experimental}

\subsection{Materials and methods}

Batches of composition (in mol\%) $60 \mathrm{P}_{2} \mathrm{O}_{5},(40-x) \mathrm{Li}_{2} \mathrm{O}$ and $x-\mathrm{Al}_{2} \mathrm{O}_{3}$ (where $x=20$ and 10) was adopted for glass 
preparation through melt quenching technique using MW and conventional resistive heating. Starting materials were $\mathrm{P}_{2} \mathrm{O}_{5}$ (Source: Di-phosphorus pentoxide, extra pure $97 \%$, Merck), lithium carbonate (source of alkaline oxide $\mathrm{Li}_{2} \mathrm{O}$, Sigma-Aldrich, $99.0 \%$ pure) and aluminium-meta-phosphate (source of $\mathrm{Al}_{2} \mathrm{O}_{3}$ and $\mathrm{P}_{2} \mathrm{O}_{5}$; Ferak Laborat, Berlin, Germany; $99.9 \%$ pure). All these raw materials were mixed thoroughly in an agate mortar and pestle to obtain a near homogeneous batch. The batches were compressed into pellets at 10 tonnes of pressure in a semi-automatic hydraulic pellet press operated within 0-20 tonnes (Steadfast International, India). The batch pellets were sintered at $600^{\circ} \mathrm{C}$ in order to eliminate the gaseous component within the raw material (i.e., $\mathrm{CO}_{2}$, $\left.\mathrm{H}_{2} \mathrm{O}\right)$.

2.1a Microwave processing: The batch for $40 \mathrm{~g}$ glass was first sintered and then placed in a silica crucible with MW transparent insulation box in atmospheric air in a multimode 6 kW MW furnace (Sairem, Labotron HTE, France). To enhance the heating rate $\left(13-15^{\circ} \mathrm{C}\right) \mathrm{MW}$ susceptors $(\mathrm{SiC})$ were placed inside the insulation box. Multimode MW furnace and cavity of net heating zone $(427 \times 427 \times 488$ $\mathrm{mm}, 88$ litres volume) was employed for this melting purpose. Temperature measurement was done by IR pyrometer $\left(250-1800^{\circ} \mathrm{C}\right)$. The forward power was controlled manually from 0.6 to $1.8 \mathrm{~kW}$. Forward power is measured by anodic voltage $\left(V_{\mathrm{a}}\right) \times$ anodic current $\left(I_{\mathrm{a}}\right) \times 70 \%$ magnetron efficiency. Reflected power, which is not directly related to material heating, was measured by a crystal detector located at the outlet of the MW isolator, controlled by an E-H tuner. Emissivity $(\varepsilon)$ was set to 0.4 for the two melting operations in MW heating. All the raw materials were melted in the temperature range of $\sim 1150-1300^{\circ} \mathrm{C}$ for $30 \mathrm{~min}$. Subsequently, the melt was poured into a preheated steel mould. The annealing followed by controlled cooling of hot glass was performed to eliminate thermal stress in a muffle furnace. Theoretical estimation of annealing temperatures was done using Sci glass software (Priven 2000 method) and these were 425 and $340^{\circ} \mathrm{C}$ for PLA1 and PLA2, respectively.

2.1b Conventional heating: The identical batches were melted in a resistive heating furnace (M/s Deltecc Inc, USA; Cavity size: Dia 200 and height $250 \mathrm{~mm}$ ) in the temperature range of $\sim 1150-1300^{\circ} \mathrm{C}$ with a heating rate of $4-5^{\circ} \mathrm{C} \min ^{-1}$. Manual stirring was employed to improve homogeneity in the glass. Glass casting and subsequent annealing have been performed as described in the earlier section. The annealed glasses were processed through cutting, grinding and polishing to get a polished glass sample of dimension $10 \times 15 \times 2 \mathrm{~mm}^{3}$. Consumption of electrical power was recorded with time from the power meter connected with the furnace. Temperature-power-time (T-P-t) profile was generated and presented in the respective following section.

\subsection{Characterization techniques}

The densities were evaluated by Gas Pycnometer Method (AccuPync II 1340, Micromeritics analysis system, USA). A gas pycnometer is a device used for measuring density or more accurately the volume of solids for different shapes (i.e., regularly shaped, porous or non-porous, monolithic, powdered, granular) employing the Boyle's Law and the Charle's Law. A gas pycnometer is also sometimes referred to as a helium pycnometer. The instrument works by measuring the amount of displaced gas. Helium gas of dew point $-67^{\circ} \mathrm{C}$ is used as a working fluid. The pressure observed upon filling the sample chamber and then discharging it into a second empty chamber allows computation of the sample solid phase volume. Gas molecules rapidly fill the tiniest pores of the sample; only the truly solid phase of the sample displaces the gas. A sample chamber of $1,10,100$ or $350 \mathrm{~cm}^{3}$ can be selected to provide the best fit with the samples. Initially, $V_{\text {cell }}$ (cavity or cell volume) and $V_{\exp }$ (volume of expanded cell or cavity) are at ambient pressure $P_{\mathrm{a}}$, and ambient temperature $T_{\mathrm{a}}$ and the valve is then closed. $V_{\text {cell }}$ is then charged to an elevated pressure $P_{1}$. The mass balance across cell $V_{\text {cell }}$ is :

$$
P_{1}\left(V_{\text {cell }}-V_{\text {samp }}\right)=n_{\mathrm{C}} R T_{\mathrm{a}}
$$

Where, $n_{\mathrm{C}}=$ the number of moles of gas in sample cell, $R=$ the gas constant, $T_{\mathrm{a}}=$ the ambient temperature.

For the expansion volume cell,

$$
P_{\mathrm{a}} V_{\exp }=n_{\mathrm{e}} R T_{\mathrm{a}}
$$

Where, $n_{\mathrm{e}}=$ the number of moles of gas in expansion volume cell, $P_{\mathrm{a}}=$ ambient pressure.

When valve is opened pressure falls to an intermediate value $P_{2}$ and mass balance is:

$$
P_{2}\left(V_{\text {cell }}-V_{\text {samp }}+V_{\text {exp }}\right)=n_{\mathrm{E}} R T_{\mathrm{a}}+n_{\mathrm{C}} R T_{\mathrm{a}}
$$

Substituting from equations (2) and (3) in equation (4), we get :

$$
P_{2}\left(V_{\text {cell }}-V_{\text {samp }}+V_{\text {exp }}\right)=P_{\text {a }} V_{\exp }+P_{1}\left(V_{\text {cell }}-V_{\text {samp }}\right)
$$

Rearranging the above equation we get:

$$
V_{\text {samp }}=V_{\text {cell }}-\frac{V_{\text {exp }}}{\left[P_{1}-P_{\mathrm{a}} / P_{2}-P_{\mathrm{a}}\right]-1}
$$

Thus, the density of glass sample is evaluated from mass and obtained volume. The measurement of density was carried out ten times for each sample and the average value is reported with error limit $( \pm 0.001)$.

X-ray diffraction analysis was performed by 94 X'Pert, PANalytical using Ni-filtered $\mathrm{CuK} \alpha$ radiation with wavelength of $1.5406 \AA$ to determine the amorphous phase of the 
samples. The scanning range was fixed from 5 to $90^{\circ} \mathrm{C}$ with a step size of $0.05^{\circ} \mathrm{C} \min ^{-1}$.

The glass transition temperature $\left(T_{\mathrm{g}}\right)$ was determined by differential scanning calorimetry (DSC) (model STA 449 F3, Netzsch-Jupiter, Germany) up to temperature $800^{\circ} \mathrm{C}$ at a heating rate of $10 \mathrm{~K} \mathrm{~min}^{-1}$ under controlled $\mathrm{N}_{2}$ atmosphere (with $60 \mathrm{ml} \mathrm{min}^{-1}$ flow rate) by using high purity re-crystallized alumina crucible as sample container with temperature measurement accuracy of $1^{\circ} \mathrm{C}$. Around $40 \mathrm{mg}$ of powder sample was taken for DSC experiments.

Refractive indices (RI) of glass samples prepared by both methods were measured at five wavelengths (473, 532, 633, 1064 and $1552 \mathrm{~nm}$ ) on Prism Coupler (Metricon Model2010, NJ, USA) fitted with five different lasers as illuminating sources. Three measurements were recorded for each wavelength and the standard deviation has been reported as error limit $( \pm 0.0001)$.

The optical transmittance spectra were recorded at room temperature on a UV-Vis-NIR spectrophotometer (Model Lambda 920, Perkin Elmer, USA) in the wavelength range 200-3000 nm.

Fourier transform infrared (FTIR) measurements were performed on FTIR spectrophotometer (Model: 1615, Perkin Elmer Corporation, USA) with a spectral resolution of $4 \mathrm{~cm}^{-1}$ over a spectral range of $400-1500 \mathrm{~cm}^{-1}$ to identify functional group and different bond.

Micro-hardness of the glasses was measured by taking micro-indentation on the polished surface of the glasses with a diamond indenter. Indentations were performed using a micro-indentation hardness testing instrument (Clemex CMT, Longueuil, Canada, accuracy in the range of $3 \%$ ) equipped with a conical Vickers indenter at an indent load of $200 \mathrm{~g}$. The diagonals of the Vickers indents were carefully measured using optical microscope and subsequently, the hardness was calculated using the standard equation for the Vickers geometry. The average hardness of all the glasses was calculated from ten micro-indentation impressions with identical loading conditions.

$$
H_{\mathrm{V}}=1.8544 \frac{P}{d^{2}},
$$

where $H_{\mathrm{V}}$ is the Vickers hardness number in $\mathrm{kg} \mathrm{mm}^{-2}, P$ is the normal load in $\mathrm{kg}$ and $d$ is the average diagonal length of the indentation in $\mathrm{mm}$.
Electrochemical impedance spectra for PLA-1C and PLA$1 \mathrm{M}$ were recorded on a galvanostat-potentiostat (PGSTAT $302 \mathrm{~N}$, Autolab, the Netherlands) in the frequency range of $100 \mathrm{kHz}$ to $0.1 \mathrm{~Hz}$ with an $\mathrm{AC}$ amplitude of $10 \mathrm{mV}$ at room temperature $\left(25^{\circ} \mathrm{C}\right)$. Initially the glass sample was ultrasonically cleaned with deionized (DI) water for $10 \mathrm{~min}$ to remove any kind of dusty particles aggregated during handling. Next, it was step-wise ultrasonically cleaned with ethanol and acetone for $10 \mathrm{~min}$ each and then it was dried over a cotton sheet and kept in a vacuum desiccator for further use. Graphite paste was uniformly coated on both sides of the glass samples and dried in the ambient temperature. Then, it was kept inside an air-oven $\left(60^{\circ} \mathrm{C}\right)$ overnight for curing the coated paste prior to recording impedance spectra.

\section{Results and discussion}

Figure 1 presents photograph of polished glass samples of dimension $10 \times 15 \times 2 \mathrm{~mm}^{3}$ of two sets of glasses obtained from conventional and MW heating. Visual appearance indicates that cord- and bubble-free transparent glass could be obtained in MW heating similar to conventional glass.

Figure 2 shows the typical relation between density and concentration of $\mathrm{Li}_{2} \mathrm{O}$ in glass $(\mathrm{mol} \%)$ for all the glass samples prepared by $\mathrm{MW}$ as well as conventional heating. It can be observed that density decreases with increasing $\mathrm{Li}_{2} \mathrm{O}$ content in glass. Lithium being the smallest alkali metal can easily depolymerize the phosphate chains creating more non-bridging oxygens (NBOs) and thereby introduces excess structural free volume. However, density of glass obtained in MW heating is found to be lower than that of conventional glasses. Time needed prior to casting the melt in MW heating is relatively more than that in resistive heating, which ensure slow cooling rate in MW heating. This slow cooling rate during glass formation lowers the density of glass in MW processing. Another reason of low density in glass may be due to less evaporation of more volatile ingredient in MW heating.

Figure 3 depicts X-ray diffractograms for all the samples. Observation of a broad hump centred around $2 \theta=25^{\circ}$ and absence of any sharp peak, confirm amorphous nature of the samples. This further reveals that in MW heating no unmelted crystalline phase (raw material) is left within the glass.

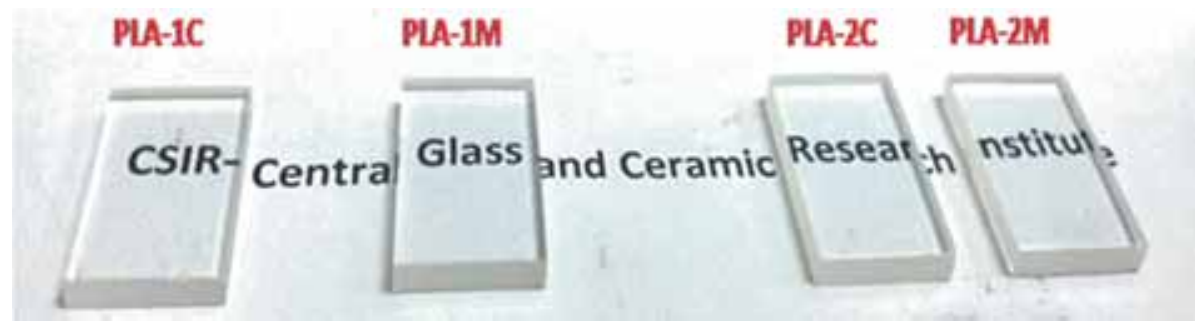

Figure 1. Photograph of polished glasses prepared in conventional heating (PLA-1C and PLA-2C) and microwave heating (PLA-1M and PLA-2M). 


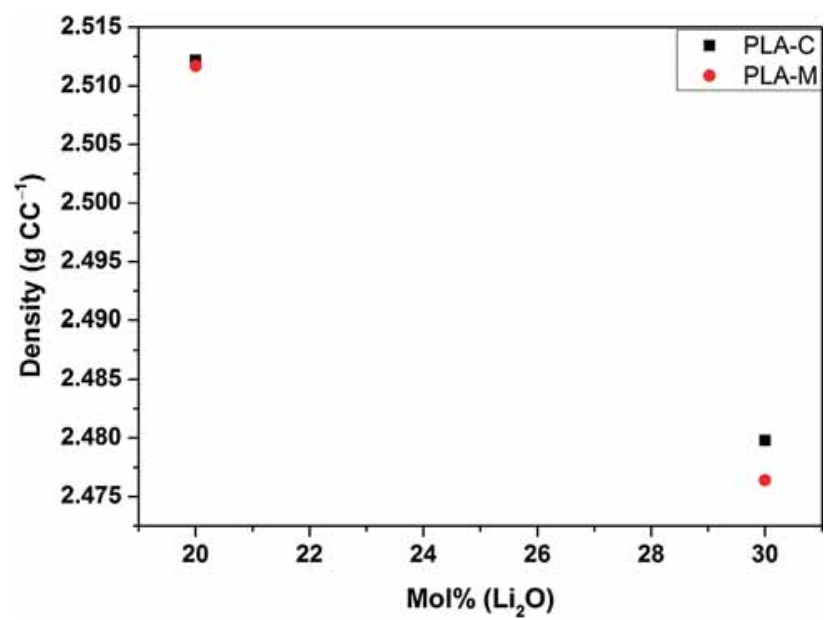

Figure 2. Plot of density with the concentration of $\mathrm{Li}_{2} \mathrm{O}(\mathrm{mol} \%)$ in both microwave and conventional heating.

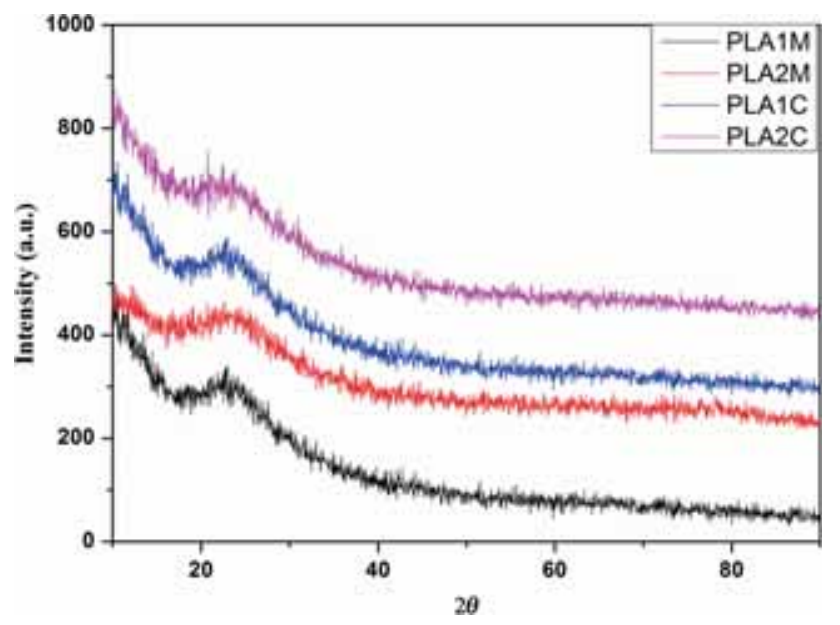

Figure 3. X-ray diffractograms of all four glass samples.

Figure 4 exhibits the DSC thermogram of all the glasses. Glass transition temperatures $\left(T_{\mathrm{g}}\right)$ of $480,470.9,434.6$ and 431.8 were found for PLA1C, PLA1M, PLA2C and PLA2M, respectively. This shows that increasing the ratio of $\mathrm{Li}_{2} \mathrm{O} / \mathrm{Al}_{2} \mathrm{O}_{3}$ decreases the $T_{\mathrm{g}}$. Lithium being modifier can reduce the glass transition temperature by breaking $\mathrm{P}-\mathrm{O}-\mathrm{P}$, $\mathrm{P}-\mathrm{O}-\mathrm{Al}$ linkages with more NBO. Both the glasses prepared in MW heating show lower $T_{\mathrm{g}}$ than conventional glasses due to a slower cooling rate during glass formation and lesser loss of ingredient by evaporation.

Figure 5 illustrates UV-Vis-NIR transmittance spectra of the studied glasses within the wavelength range of 200-3000 $\mathrm{nm}$. UV-Vis transmission spectra for composition 1 are shown in figure $5 \mathrm{a}$ and for composition 2 in figure $5 \mathrm{~b}$. Transmittance in glass is found to be similar ( $>85 \%$ within $500-2000 \mathrm{~nm}$ ) in both heating routes indicating similar optical transmittance that can be achieved in the glass prepared in MW heating.

The RI have been measured at five different wavelengths $(473,532,633,1064$ and $1552 \mathrm{~nm})$ and curve fitting is obtained using Cauchy's curve fitting equation (7), as shown

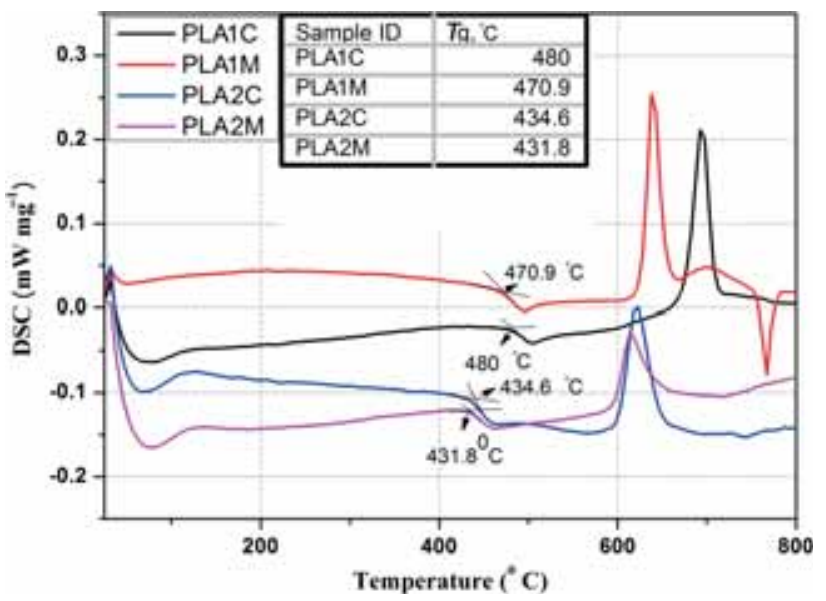

Figure 4. Differential scanning calorimetric thermogram of all the glasses obtained from both microwave and conventional heating.

in figure 6. Figure 6a and $\mathrm{b}$ shows RI with curve fitting for composition 1 and composition 2, respectively. Figure 6a and $\mathrm{b}$ illustrates lower RI in glass melted in MW heating than conventional heating for both the compositions. Lower density corroborates less RI in both the glasses melted in MW route than in the conventional method.

$$
n(\lambda)=A+\frac{B}{\lambda^{2}}+\frac{C}{\lambda^{4}}+\cdots
$$

where, $n$ is the refractive index at wavelength $\lambda \mathrm{nm}$. Equation 7 has been used to plot the refractive index curves.

Figure 7 displays FTIR reflectance spectra for all samples at room temperature from 400 to $1500 \mathrm{~cm}^{-1}$. The spectra reveal the presence of phosphate tetrahedral, $\mathrm{Al}-\mathrm{O}-\mathrm{Al}$ bridging, octahedral $\mathrm{AlO}_{6}$ and tetrahedral $\mathrm{AlO}_{4}$ vibration at 490, $720-779,918,1094,1140$ and $1288 \mathrm{~cm}^{-1}$. The vibrational band appearing at $1288 \mathrm{~cm}^{-1}$ represents $\mathrm{P}=\mathrm{O}$ asymmetric stretching for the $\mathrm{PO}^{2}$ chain [25]. The band appearing within $720-779 \mathrm{~cm}^{-1}$ is due to symmetric stretching for P-O-P bridges [26]. The band at $\sim 1094$ has been shifted to $1140 \mathrm{~cm}^{-1}$ for $20 \mathrm{~mol} \%$ of $\mathrm{Li}_{2} \mathrm{O}$. Band originating at $\sim 490$ and $720-779 \mathrm{~cm}^{-1}$ are due to the vibration of octahedral $\mathrm{AlO}_{6}$ and tetrahedral $\mathrm{AlO}_{4}$ coordinated sites, respectively [27]. Asymmetric stretching of $\mathrm{PO}_{3}$ groups in $\left(\mathrm{PO}_{4}\right)_{3}^{-}$units contributed the weak band at $1094 \mathrm{~cm}^{-1}$ [28]. Band at $\sim 1140 \mathrm{~cm}^{-1}$ is ascribed to the symmetric and asymmetric vibrations of $\mathrm{P}=\mathrm{O}$ in $\mathrm{PO}^{2}$ chain. The band appeared at $\sim 918 \mathrm{~cm}^{-1}$ is attributed to the asymmetric vibrational stretching modes of bridging oxygen of $\mathrm{P}-\mathrm{O}-\mathrm{P}$ bonds. The glasses studied at $20 \mathrm{~mol}^{2} \mathrm{Li}_{2} \mathrm{O}$ (PLA-1) produced a different vibration at $1140 \mathrm{~cm}^{-1}$, which is unusual for the glasses prepared from composition- 1 . This may be due to the structural changes associated with the decrease of $\mathrm{PO}_{3}$ units in glass.

Figure 8 depicts the micro-indentation images of all four glasses prepared in both heating. Micro-hardness is estimated at 5.23 GPa for PLA1M and 4.66 GPa for PLA2M, whereas it is evaluated as 4.92 and $4.24 \mathrm{GPa}$ for PLA1C and 

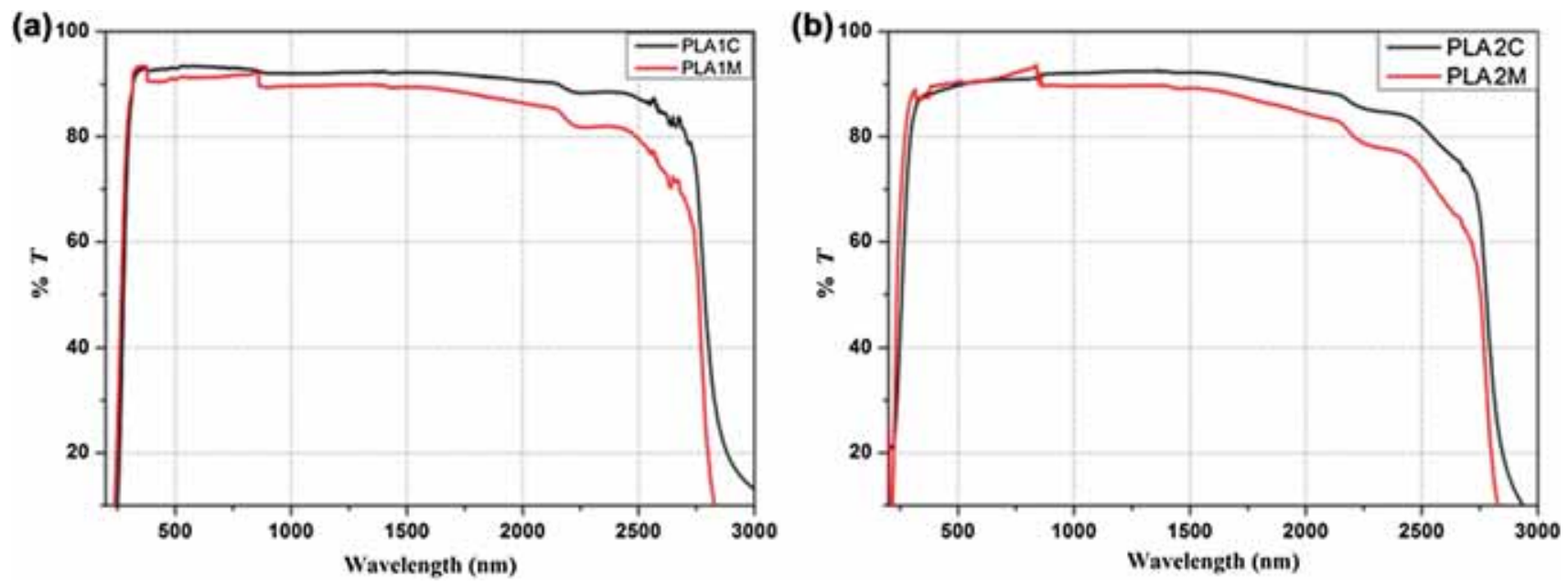

Figure 5. UV-Vis-NIR transmittance spectra of all the studied glasses prepared in both heating routes (a) for composition-1 (PLA1) and (b) composition-2 (PLA2).
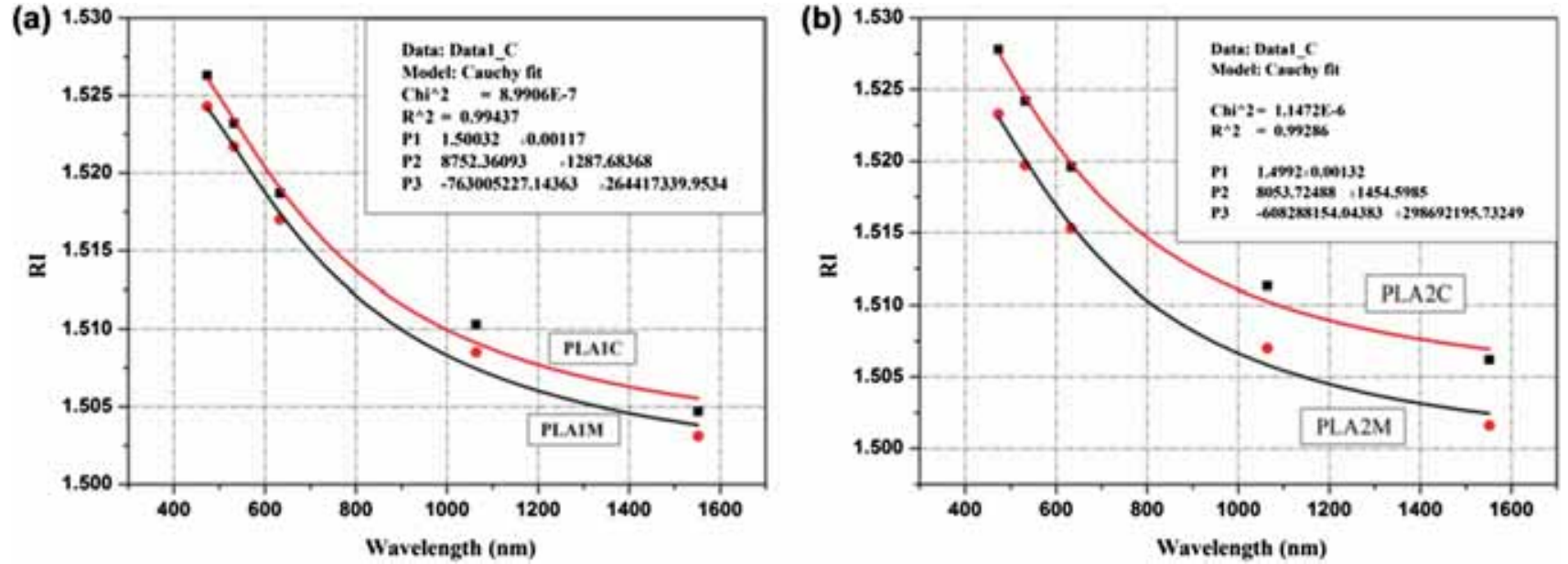

Figure 6. RI at five different wavelengths fitted with Cauchy fitting equation (a) PLA1C and PLA1M and (b) PLA2C and PLA2M.

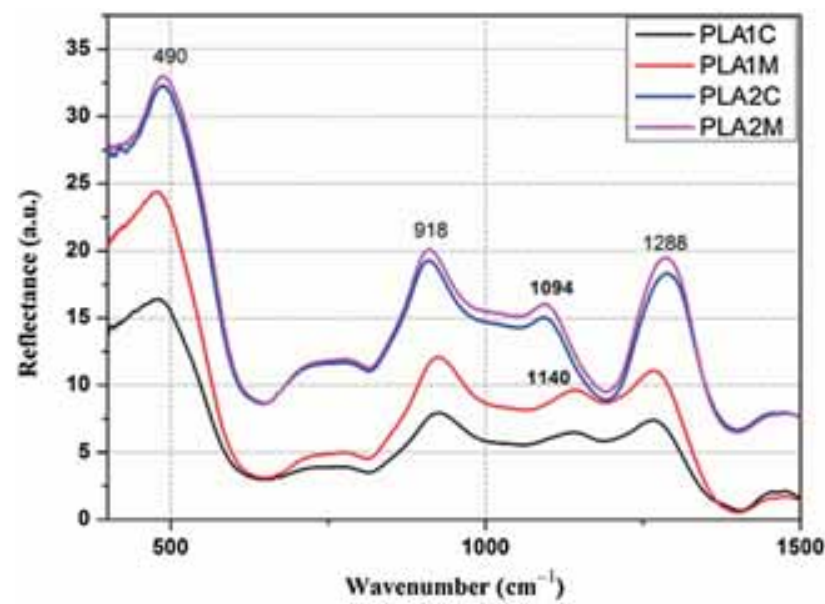

Figure 7. FTIR reflectance spectra for all the studied glasses melted in microwave and conventional heating.
PLA2C, respectively. This indicates that MW heating influences improving micro-hardness in glass. This observation is in consistence with borosilicate glass melted in MW heating $[29,30]$. It may be assumed that MW heating, being fundamentally different from conventional heating, generates heat within the material due to molecular interaction and thereby influences its structure. This structural difference may influence its mechanical properties. It may also be assumed that compositional homogeneity in MW prepared glasses causes slightly improved micro-hardness. However, further study is under progress to determine the cause of higher microhardness in glass melted in this method.

Useful information about dynamical processes involving ionic motion can be obtained from impedance measurement of ionic materials. Figure 9a shows the Nyquist plots for the glass samples (both MW and resistive melting), obtained by plotting the real $v s$. imaginary impedance, recorded by 

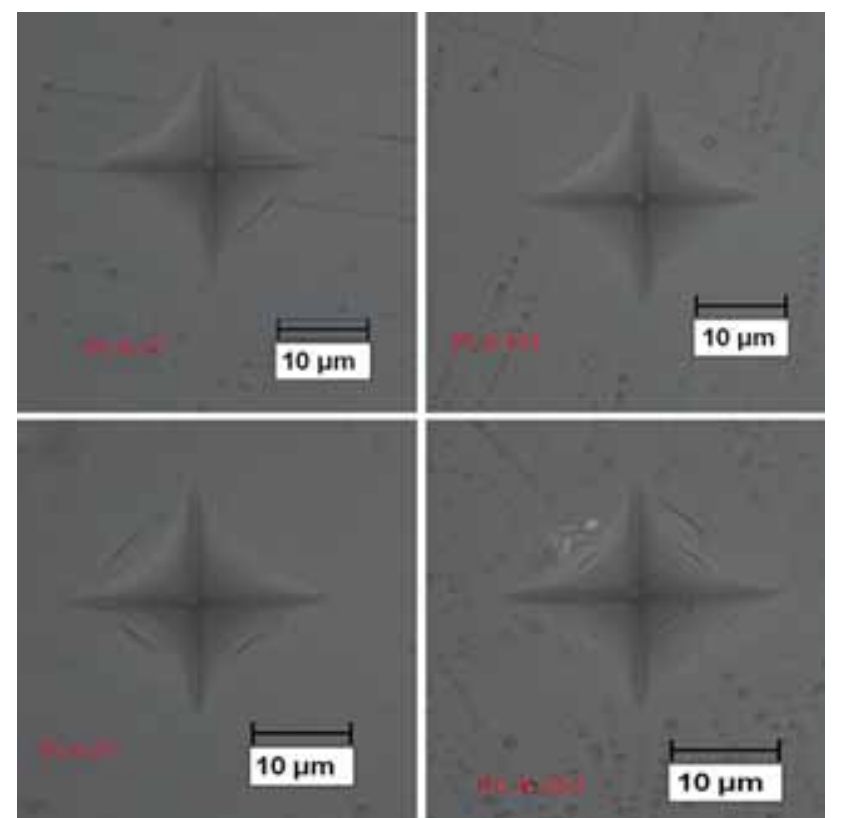

Figure 8. Micro indentation images of all glass samples prepared in both microwave and resistive heating.

an impedance analyser with an AC perturbation of $10 \mathrm{mV}$. The observed spectra are typical of ion-conducting glasses [31-33]. Observation of a single semicircle without any tail in the low frequency region suggests a narrow distribution of relaxation times involving a single mechanism of polarization and can be represented by an equivalent circuit model consisting of a capacitor parallel with a resistor. The diameter of the semicircle represents the resistance $(R)$ and thereby, DC conductivities can be calculated by using the formula $l / R A$,
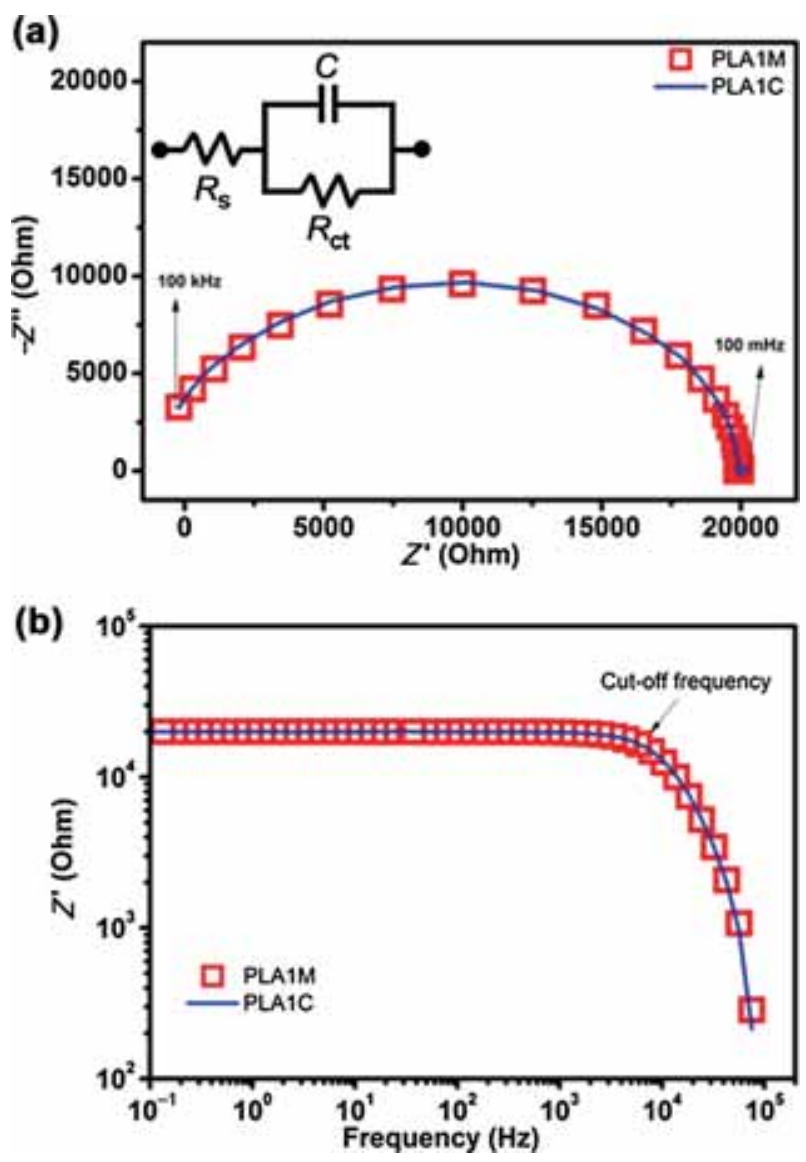

Figure 9. (a) Nyquist plots and (b) Bode plots for PLA1M and PLA1C glass samples obtained from impedance measurements with an $\mathrm{AC}$ amplitude of $10 \mathrm{mV}$. The equivalent circuit model used to fit the impedance data is shown in the inset of $\mathbf{a}$.

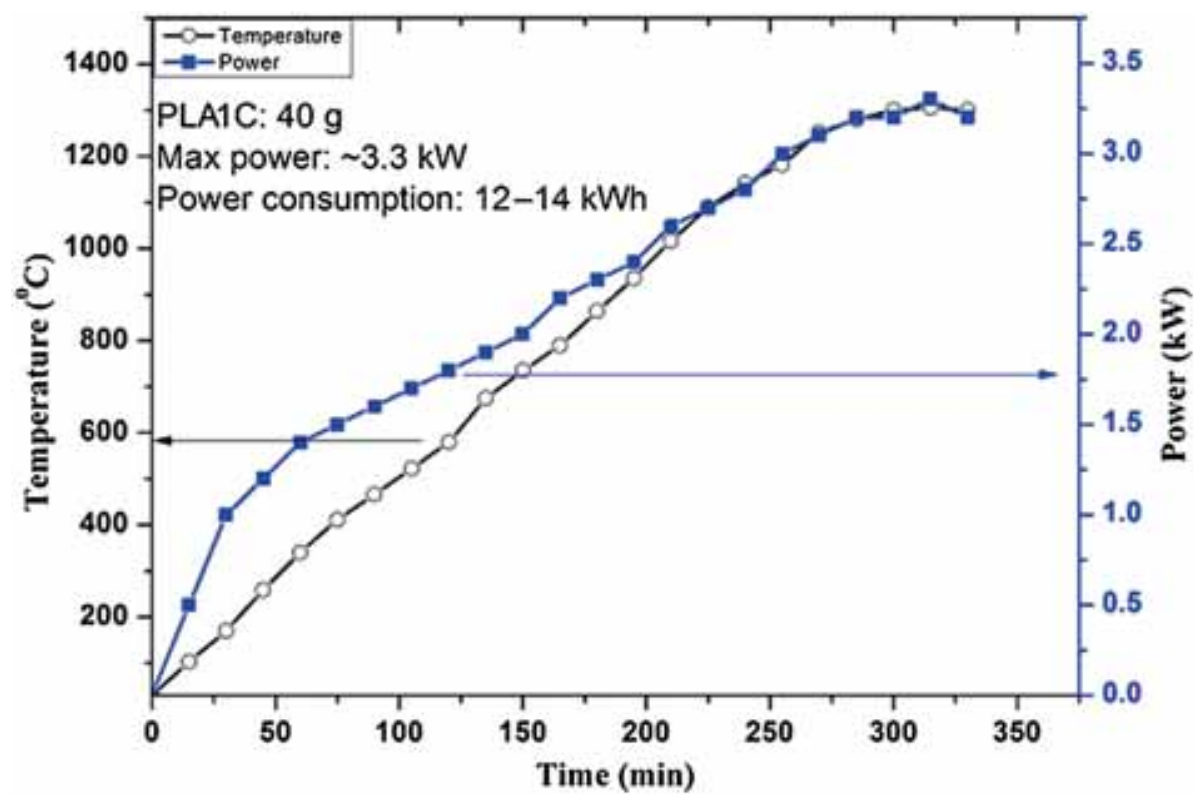

Figure 10. T-t-P profile of glass melted in conventional resistance heating furnace. 

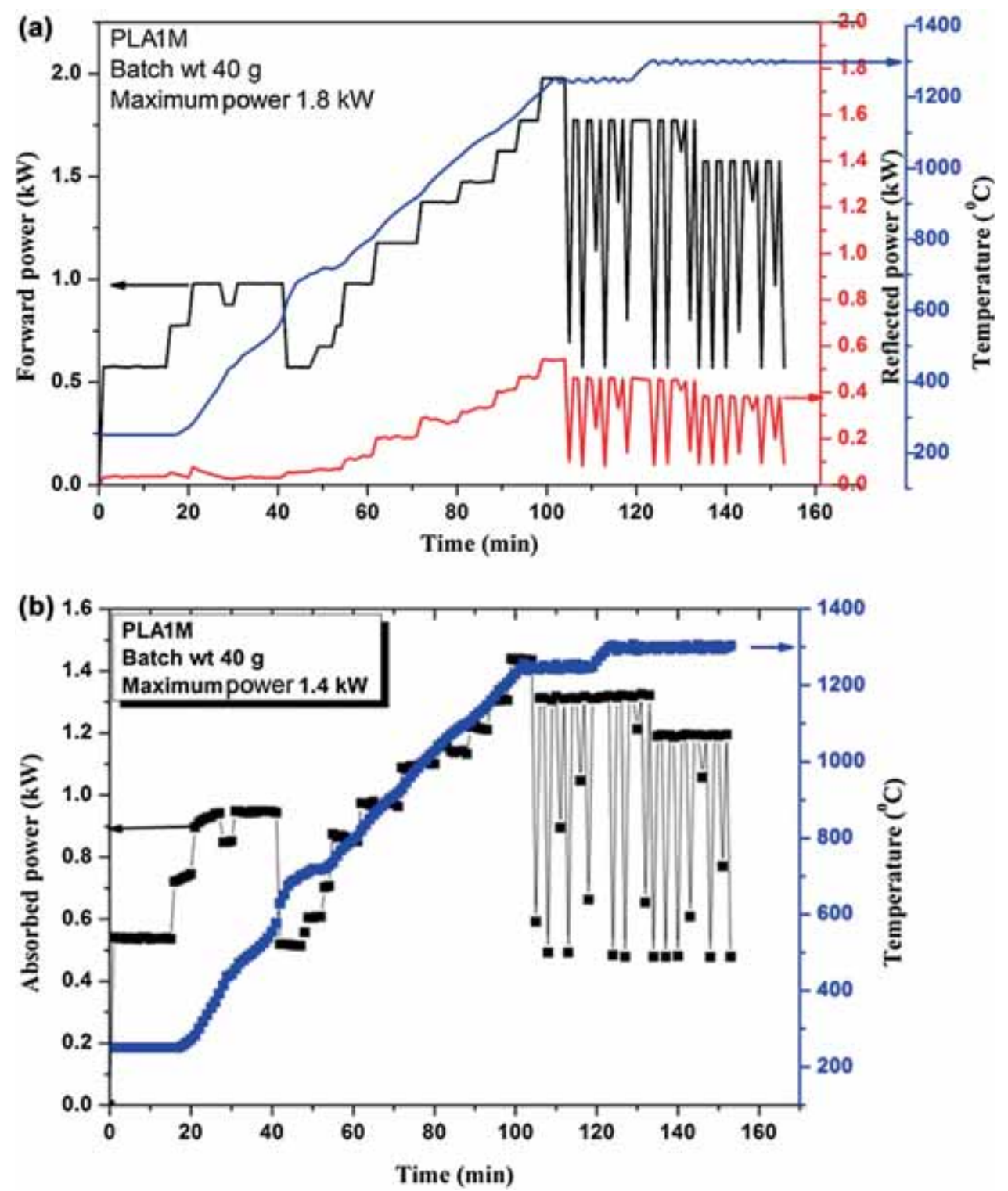

Figure 11. (a) Temperature, forward and reflected power with time for the melting of glass in MW furnace and (b) $\mathrm{T}-\mathrm{t}-\mathrm{P}$ profile for the studied glass in microwave furnace.

where $A$ is the surface area and $l$ is the distance between two electrodes, i.e., sample thickness. Ionic conductivity of $\sim 6.7 \times 10^{-6} \mathrm{~S} \mathrm{~cm}^{-1}$ has been obtained for both PLA-1C and PLA-1M indicating that the change in melting method from resistive heating to MW heating does not affect the ionic conductivity. The impedance data have been fitted with an equivalent circuit as shown in the inset of figure 9a. The impedance parameter resistance $(R, \mathrm{k} \mathrm{Ohm})$ is obtained as 20.4 for PLA$1 \mathrm{C}$ and 20.3 for PLA-1M. The capacitance (C) is evaluated as 508 and $512 \mathrm{pF}$ for PLA-1C and PLA-1M, respectively.

As the Nyquist plot does not provide any information about the frequency, Bode plots for the glass samples are shown in figure $9 \mathrm{~b}$, which relates the frequency $(\omega)$ with the real part of impedance $\left(Z^{\prime}\right)$. When the slope $(n)$ of the plot approaches zero, it corresponds to a pure capacitor while a unit value of the slope corresponds to a pure resistive behaviour. We can see from figure $9 \mathrm{~b}$ that the cut off frequency $(5.963 \mathrm{kHz})$ is similar for samples melted by conventional resistive heating or by MW heating. Both the samples showed capacitive nature below this frequency $(5.963 \mathrm{kHz})$ and above it the samples were fully resistive in nature. Therefore, it appears that change in melting method from conventional resistive heating to $\mathrm{MW}$ heating does not significantly alter the electrical properties.

\section{Temperature-time-power profile}

A temperature, time and power (T-t-P) profile is recorded during melting in resistance heating furnace and shown in figure 10. Figure 10 depicts that the maximum electrical 
power demand is $3.3 \mathrm{~kW}$ with total power $14 \mathrm{kWh}$ in a resistive heating furnace of cavity size $\sim 8$ litres (Dia: 200 and height $250 \mathrm{~mm}$ ). Furthermore, the melting time for completion of this melting is recorded $\sim 6 \mathrm{~h}$ (without cooling cycle. This longer processing time is because of low heating rate $\left(4-5^{\circ} \mathrm{C} \mathrm{min}^{-1}\right)$ to protect the heating element and furnace refractory and more holding/soaking time in conventional melting.

$\mathrm{T}-\mathrm{t}-\mathrm{P}$ profile recorded during melting of PLA-1M in MW furnace is presented in figure 11a. It is clearly seen from figure 11a that maximum forward power drawn by the MW furnace is $1.8 \mathrm{~kW}$. Therefore, actual electrical power consumed is $\sim 2.5 \mathrm{~kW}$ in 88 litres MW cavity with $6 \mathrm{~kW}$ magnetron source. Reflected power, which is lost within the cavity without being absorbed by the materials, remains in the range of $10-15 \%$ of forward power. Actual power absorbed by the material is estimated by eliminating reflected power from forward power. Actual power absorption by the material (and partially by insulation material) is presented in figure $11 \mathrm{~b}$. Furthermore, total duration of the melting is recorded at $\sim 2 \mathrm{~h}$ $30 \mathrm{~min}$, which is one-third of the time taken in conventional resistive heating furnace. Actual electrical power consumption in the MW furnace can be minimized by minimizing reflected power with the help of a E-H tuner. It can further be reduced by employing smaller MW cavity size (i.e., volume) with lower source of magnetron capacity.

\section{Conclusion}

Lithium phosphate glasses with varying ratio of $\mathrm{Li}_{2} \mathrm{O} / \mathrm{Al}_{2} \mathrm{O}_{3}$ were prepared in $\mathrm{MW}$ and conventional heating. A comparative property investigation has been presented in this report. Investigation of optical, electrical and structural property indicates similar glasses were obtained in both the methods. Increasing the modifier content decreases density, microhardness in glass and improved micro-hardness is obtained in MW heating. However, $T_{\mathrm{g}}$ reduces with increasing $\mathrm{Li}_{2} \mathrm{O}$ content and it is observed more in conventional than in MW heating. The electrical power consumed in 88 litres cavity MW furnace is $5 \mathrm{kWh}$, whereas it is $14 \mathrm{kWh}$ in resistance heating furnace of 8 litres cavity volume. Lost energy or reflected power can be minimized within the range of $10-15 \%$ of forward power in the MW cavity. Moreover, significant observation in this study shows that much less melting time ( $2 \mathrm{~h} 30$ $\mathrm{min}$ ) in MW route has potential to minimize the production cost of glass in this method.

\section{Acknowledgements}

Financial support from the Council of Scientific and Industrial Research (CSIR), India (Project ESC0202) is gratefully acknowledged. We would like to thank the Director of CSIRCentral Glass and Ceramic Research Institute, Kolkata, India, for his kind support.

\section{References}

[1] Mondal A, Agrawal D and Upadhyaya A 2010 J. Microw. Power Electromagn. Energy 4428

[2] Yadoji P, Peelamedu R, Agrawal D and Roy R 2003 Mater. Sci. Eng. B 98269

[3] Zumeta I, Ayllon J A, Gonzalez B, Domenech X and Vigil E 2009 Solar Energy Mater. Solar Cells 931728

[4] Das S, Mukhopadhyay A K, Datta S and Basu D 2006 Trans. Ind. Ceram. Soc. 65105

[5] Das S, Mukhopadhyay A K, Datta S and Basu D 2008 J. Eur. Ceram. Soc. 28729

[6] Oghbaei M and Mirzaee O 2010 J. Alloys Compd. 494175

[7] Das S, Mukhopdhyay A K, Dutta S and Basu D 2009 Bull. Mater. Sci. 321

[8] Kharissova O K, Kharisov B I and Valde's J J R 2010 Ind. Eng. Chem. Res. 491457

[9] Wong W L E and Gupta M 2015 Technologies 31

[10] Bhattacharya M and Basak T 2016 Energy 97306

[11] Cheng J, Agarwal D, Roy R and Jayan P S 2000 J. Mater. Process. Technol. 10826

[12] Shukla A K, Mondal A and Upadhyaya A 2010 Sci. Sinter. 42 99

[13] Wang J S, Jeng J S and Ni C T 2009 J. Non-Cryst. Solids 355 780

[14] Mandal A K and Sen R 2015 Technologies 3111

[15] Mandal A K and Sen R 2016 Mater. Manuf. Process. 321

[16] Mandal A K, Sinha P K, Sen S, Mandal S, Guha C and Sen R 2014 J. Chem. Chem. Eng. 8349

[17] Mandal A K, Balaji S and Sen R 2014 J. Alloys Compd. 615 283

[18] Jeng J S and Ni C T, 2009 J. Non-Cryst. Solids 355780

[19] Day D E, Wu Z, Ray C S and Hrma P 1998 J. Non-Cryst. Solids 2411

[20] Campbell J H, Suratwala T I, Thorsness C B, Hayden J S, Thorne A J, Cimino J M et al 2000 J. Non-Cryst. Solids 263-264 342

[21] Zhang X W, Wang C, Appleby A J and Little F E 2002 J. Power Sources 112209

[22] Mandal A K, Biswas K, Annapurna K, Guha C and Sen R 2013 J. Mater. Res. 281955

[23] Thostenson E T and Chou T W 1999 Compos. Part A 30 1055

[24] Sutton W H 1989 Cer. Bull. 68376

[25] Saoüt G L, Simon P, Fayon F, Blinn A and Vaills Y $2002 J$. Raman Spectr. $\mathbf{3 3} 740$

[26] Dayanand C, Bhikshamaiam G, Tyagaraju V J, Salegram M and Krishna Murthy A S R 1996 J. Mater. Sci. 311945

[27] Belkébir A, Rocha J, Esculcas A P, Berthet P, Gilbert B, Gabelica Z et al 1999 Spectrochim. Acta Part A 551323

[28] Almieda R M and Mackenzie J D 1980 J. Non-Cryst. Solids 40 535

[29] Mandal A K, Agrawal D and Sen R 2013 J. Non-Cryst. Solids 371-372 41

[30] Mandal A K, Sen S, Mandal S, Guha C and Sen R 2015 Int. J. Green Energy 121280

[31] Sanghi S, Sheoran A, Agarwal A and Khasa S 2010 Phys. B Condens. Matter 4054919

[32] Prasad A and Basu A 2013 J. Adv. Ceram. 271

[33] Rathore M and Dalvi A 2013 Solid State Ion. 23950 